\title{
Akut Koroner Sendromlu Hastalarda Plazma von Willebrand Faktör Düzeyi ile Koroner Arter Hastalığı Ciddiyeti Arasındaki İlişkisi
}

\section{The Relationship between Plasma von Willebrand Factor Level and Severity of Coronary Artery Disease in Patients with Acute Coronary Syndrome}

\author{
Mustafa Begenc TASCANOV 1 일
}

${ }^{1}$ Harran Üniversitesi Tıp Fakültesi, Kardiyoloji Anabilim Dalı, Osmanbey Kampüsü, Şanlıurfa/Türkiye

öz.

Amaç: Koroner arter hastalığının yaygınlığını ve ciddiyetini değerlendirmek için anjiyografik bir skorlama sistemi olan Gensini skoru kullanılmaktadır. Yüksek Gensini skoru ve vonWillebrand faktör düzeyi akut koroner sendromlu hastalarda kötü kardiyak olaylar ile ilişkilidir. Bu çalışmada akut koroner sendromlu hastalarda Gensini skoru ile vonWillebrand faktör düzeyi arasındaki ilişkiyi araştırmayı planladık.

Materyal ve Metot: Çalışmaya akut koroner sendrom tanısıyla koroner anjiyografi yapılan 141 hasta dahil edildi. Gensini skoru $<32$ olan hastalar grup 1, gensini skoru $\geq 32$ olan hastalar ise grup 2 olarak tanımlandı. Her iki grup, anjiyografik özellikler ve plazma vonWillebrand faktör düzeyleri açısından karşılaştırıldı

Bulgular: Grup 1 hastalar ile karşılaşııııldıklarında, grup 2 hastalarda vonWillebrand faktör düzeyi anlamlı olarak daha yüksek idi (140 IU [101-149]'e karşın 120 IU [100-134], P=0.010). Korelasyon analizinde gensini skoru ile vWF arasında pozitif bir korelasyon mevcuttu $(r=0.228, p=0.007)$. Çok değişkenli lojistik regresyon analizinde, vWF yüksek Gensini skorunun bağımsız bir öngördürücüsü olarak tespit edildi (odds oranı, 1.013; \% 95 güven aralığı, $1.002-1.026, \mathrm{P}<0.027$ ). vonWillebrand faktör sınır değerinin $\geq 128$ IU alınması, \% 59 duyarlılık ve \% 63 özgüllük ile yüksek gensini skorunu öngördü.

Sonuç: Akut koroner sendromlu hastalarda yüksek von Willebrand faktör seviyesi bağımsız olarak yüksek gensini skoru ile ilişkilidir.

Anahtar Kelimeler: Akut koroner sendrom, Gensin skoru, von Willebrand faktör

\section{Abstract}

Background: Gensini score, an angiographic scoring system, is used to evaluate the extent and severity of coronary artery disease. High Gensini score and von Willebrand factor level are associated with poor cardiac events in patients with acute coronary syndrome. In this study, we aimed to investigate the relationship between Gensini score and von Willebrand factor level in patients with acute coronary syndrome

Materials and Methods: The study included 141 patients with acute coronary syndrome who underwent coronary angiography. Patients with gensini score $<32$ were defined as group 1, while patients with gensini score $\geq 32$ were defined as group 2. Angiographic characteristics and plasma von Willebrand factor level were compared between two groups.

Results: When compared to group 1 patients, group 2 patients had significantly higher levels of von Willebrand factor (140 IU [101-149] vs. 120 IU [100-134], $P=0.010)$. In correlation analysis, Gensini score and von Willebrand factor level was positively correlated $(r=0.228, p=0.007)$. Multivariate logistic regression analysis demonstrated that Willebrand factor was an independent predictor of high gensini score (odds ratio, 1.013; $95 \%$ confidence interval, 1.002 - 1.026, P <0.027]. von Willebrand factor level $\geq 128 \mathrm{IU}$ predicted high gensini score with a sensitivity of $59 \%$ and specificity of $63 \%$.

Conclusion: High von Willebrand factor level is independently associated with high gensini score in patients with acute coronary syndrome.

Keywords:Acute coronary syndrome, Gensini score, von Willebrand factor
Sorumlu Yazar I

Corresponding Author

Mustafa Beğenç Taşcanov

Harran Üniversitesi Tıp Fakültesi

Kardiyoloji Anabilim Dalı,

Osmanbey Kampüsü,

63300 Şanlıurfa/Türkiye

Tel: 04143444444 (5490)

Fax: 04143444444

E-mail: drbegenc@gmail.com

Geliş tarihi / Received:22.09.2019

Kabul tarihi / Accepted: 25.10.2019

DOI: 10.35440/hutfd.623232 


\section{Giriş}

Ateroskleroz ve en önemli komplikasyonu olan akut koroner sendrom, kardiyovasküler hastalıkların tedavisinde önemli gelişmelere rağmen, tüm dünyada erkek ve kadınlarda önemli morbidite ve mortaliteye neden olmaya devam etmektedir (1). Endotelyal disfonksiyon, enflamasyon ve artmış koagülasyon aktivitesinin aterosklerotik sürecin başlaması ve ilerlemesiyle olan ilişkisi ortaya konulmuştur (2). von Willebrand faktör (VWF), kandaki seviyesi kolaylıkla ölçülebilen, kronik inflamasyonun akut alevlenmesine cevap olarak artan bir proinflamatuvar belirteçtir. vWF; trombosit ve lökösitlerin agregasyonunu, adezyonunu ve damar düz kas hücrelerinin proliferasyonunu uyararak endotel disfonksiyonuna neden olur (3-4). Daha önce yapılan çalışmalarda, plazma vWF düzeyinin AKS'lu hastalarda stabil koroner arter hastalığı olanlara göre daha yüksek olduğu ve yüksek plazma vWF düzeylerinin kötü prognozla ilişkili olduğunu gösterilmiştir (5-9).

Koroner arter hastalığının yaygınlığını ve ciddiyetini değerlendirmek için anjiyografik bir skorlama sistemi olan Gensini skoru (GS) kullanılmaktadır. AKS'lu hastalarda başvuru anındaki yüksek GS'nin kötü kardiyak olaylar ile ilişkili olduğu bilinmektedir $(10,11)$. Literatürde AKS ile başvuran hastalarda vWF düzeyi ile GS arasındaki ilişkiyi inceleyen çalışmalar çok sınırlıdır. Bu çalışmadaki amacımız, AKS ile başvuran hastalarda koroner arter hastalığının yaygınlığı ve ciddiyetinin bir göstergesi olan GS ile vWF düzeyi arasındaki ilişkiyi incelemektir.

\section{Materyal ve Metot}

\section{Çalışma popülasyonu}

Çalışmamıza, kliniğimize akut koroner sendrom tanısıyla başvuran 141 hasta dahil edildi. Tüm hastalara ait bazal demografik özellikler kayıt edildi. Daha önce bilinen koroner arter hastalığı, kalp yetmezliği, ciddi kalp kapağı hastalığı, romatizmal ve hematolojik hastalığı olan, antiagregan ve antikoagulan tedavi alan hastalar ve çalışmaya katılmak için rıza göstermeyenler çalışma dışı bırakıldı. Hastalar daha önce diyabet tanısı almış ve tedavi edilmişlerse ve/veya açlık kan şekeri seviyesi $\geq 126 \mathrm{mg} / \mathrm{dL}$ ise tip II diabetes mellitus olarak kabul edildi. Hastalar önceden bilinen hipertansiyona sahipse, antihipertansif tedavi kullanıyorlarsa ya da sistolik kan basınçları $\geq 140 \mathrm{mmHg}$, diyastolik kan basınçları $\geq 90 \mathrm{mmHg}$ ise hipertansiyon olarak kabul edildiler. Çalışma yerel etik kurul tarafından onaylandı ve Helsinki Bildirgesi'nin kurallarına uygun olarak uygulandı. Tüm hastalardan yazilı bilgilendirilmiş onam alındı.

\section{Biyokimyasal analiz}

En az sekiz saatlik bir açlık sonrası sabah venöz kan örnekleri alındı ve standart laboratuvar yöntemleri kullanılarak analiz edildi. Ek olarak, plazma vWF düzeyinin çalışılması amacıyla da hemogram tüpüne venöz kan örneği alındı. Alınan bu örnekler, 3000 rpm'de 10 dakika santrifüj edildi ve plazma analiz gününe kadara $-80^{\circ} \mathrm{C}$ 'de saklandı. Daha sonra, tüm katılımcıların vWF seviyeleri aynı anda ve aynı plazma örnekleriyle çalışıdı. Plazma vWF seviyeleri, ELISA yönetimi kullanılarak ölçüldü ( Dako, Glostrup, Denmark). Inflamasyon belirteçleri olarak CRP (C-reaktif protein), ESH (Eritrosit sedimentasyon hızı) ve BK (Beyaz küre) belirlendi.

\section{Koroner anjiyografi}

Tüm hastalara standart Judkins tekniği ile femoral veya radiyal yaklaşımla koroner anjiyografi yapıldı. Tüm anjiyografik veriler iki bağımsız kardiyolog tarafından analiz edildi. KAH'nın yaygınlığı ve ciddiyeti GS ile değerlendirildi. Gensini skoru; koroner lezyonunu stenoz derecesi ve stenoz lokalizasyonuna göre puanlanarak hesaplandı. Stenoz derecesinin <\%25 olması 1 puan, $\% 26-50$ arasında olması 2 puan, $\% 51-75$ arasında olması 4 puan, $\% 76$ 90 arasında olması 8 puan, \%91-99 arasında olması 16 puan ve total oklüzyon olması ise 32 puan olarak değerlendirildi. Daha sonra her bir ana koroner arter ve her bir segment için tanımlanmış olan katsayı ile çarpıldı (Sol ana koroner lezyonu için 5 puan, proksimal sol ön inen dal ve sol sirkumfleks arter için 2.5 puan; orta sol inen arter lezyonu için 1.5 puan; birinci diyagonal dal ve obtus marjinal dalları ve sağ koroner arter için 1 puan; ikinci diyagonal ve sol sirkumfleks arter posterolateral dal için 0.5 puan) ve çıkan sonuçlar toplanarak her hasta grubunun GS elde edildi (11). Hastalar GS'ye göre iki sınıfa bölündü: grup 1 (GS <32 olanlar, hafif $K A H)$ ve grup 2 ( $G S \geq 32$ olanlar, ciddi KAH) (12).

\section{İstatistiksel analizler}

Tüm veriler IBM SPSS Statistics 20 (Chicago, IL, ABD) kullanılarak analiz edildi. Verilerin normal dağııımını test etmek için Kolmogorov-Smirnov testi kullanıldı. Sürekli değişkenler ortalama \pm SD ve/veya median (interquartile range) olarak ifade edildi ve Mann-Whitney $U$ veya Student $t$ testleri ile karşılaştırıldı. Kategorik değişkenler sayı ve yüzde olarak ifade edildi ve ki-kare testi ile karşılaştırıldı. GS'nin diğer sürekli değişkenlerle korelasyonunu belirlemek için Spearman korelasyon katsayısı kullanıldı. Yüksek GS'nin bağımsız prediktörlerini belirlemek için çok değişkenli lojistik regresyon analizi yapıldı. vWF seviyesinin optimum cut-off değerini belirlemek için receiver operating characteristic (ROC) analizi yapıldı. $P$ değerinin $0.05^{\prime}$ in altında olması istatistiksel olarak anlamlı kabul edildi.

\section{Bulgular}

Çalışmaya toplam 141 hasta dâhil edildi. Hastaların demografik ve klinik özellikleri klinik özellikleri Tablo 1'de verilmiştir. Her iki grup arasında bazal demografik özellikler açısından anlamlı bir farklılık tespit edilmedi. Ancak, grup 1'deki hastalar ile karşılaştırıldıklarında, grup 2'deki hastalarda GS anlamlı olarak daha yüksek idi $(p=0.001)$. 
Çalışma gruplarının biyokimyasal ve ekokardiyografik özellikleri Tablo 2'de gösterilmektedir. Grup 2'deki hastalarda vWF (140 IU [101-149]'e karşın 120 IU [100-134], $\mathrm{P}=0.010), \quad \mathrm{BK}(10.5$ [8-15]'e karşın 9.7 [7-12.3], $\mathrm{P}=$ 0.032), CRP (20 mg/dL [9-52]'e karşın $11 \mathrm{mg} / \mathrm{dL}$ [4-37], $\mathrm{P}=0.038)$ ve ESH (20 [14-29]'e karşın 14 [10-23], $\mathrm{P}=0.007$ ) anlamlı olarak daha yüksek idi. Yapılan korelasyon analizinde, gensini skoru ile vWF $(r=0.228, p=$ $0.007)$ ve ESH $(r=0.222, p=0.010)$ arasında pozitif yönde korelasyon olduğu görüldü (Tablo 3).

Tablo 1. Çalışmaya alınan hastaların demografik ve klinik özelliklerinin karşılaştııılması

\begin{tabular}{lccc}
\hline & $\begin{array}{c}\text { Grup 1 } \\
\text { (n=73) }\end{array}$ & $\begin{array}{c}\text { Grup 2 } \\
\text { (n=68) }\end{array}$ & P \\
\hline Yaş, yıl & $59(52-68)$ & $60(50-69)$ & 0.944 \\
Cinsiyet, erkek (\%) & $60(82)$ & $52(77)$ & 0.401 \\
Vücüt kitle indeksi & $26(24-28)$ & $26(25-29)$ & 0.254 \\
(kg/m²) & & & \\
Aile öyküsü (\%) & $13(18)$ & $16(24)$ & 0.510 \\
Sigara (\%) & $35(48)$ & $30(44)$ & 0.650 \\
Diyabet (\%) & $17(23)$ & $15(22)$ & 0.862 \\
Hiperlipidemi (\%) & $22(30)$ & $22(32)$ & 0.777 \\
Hipertansiyon (\%) & $34(47)$ & $25(37)$ & 0.240 \\
Gensini skoru & $13(6-20)$ & $51(37-63)$ & 0.001 \\
Tanı & & & 0.883 \\
USAP (\%) & $24(33)$ & $16(24)$ & \\
NSTEMI (\%) & $12(16)$ & $12(18)$ & \\
STEMI (\%) & $37(51)$ & $40(59)$ &
\end{tabular}

Grup 1 (Gensini skoru <32 olanlar, hafif koroner arter hastalığı) ;Grup 2 (Gensini skoru $\geq 32$ olanlar, ciddi koroner arter hastalığı ); USAP: Unstable anjina pektoris, NSTEMI: ST yükselmesiz miyokard infarktüsü, STEMI: ST yükselmeli miyokard infarktüsü.

Yüksek GS'nin bağımsız öngördürücülerini belirlemek amacıyla çok değişkenli lojistik regresyon analizi yapıldı. Çok değişkenli lojistik regresyon analizinde vWF'un, yüksek GS'yi bağımsız bir şekilde öngördürdüğü tespit edildi [odds oranı, 1.013; \% 95 güven aralığı: 1.002 - 1.026, P $<0.027$ ] (Tablo 4). Yüksek GS'yi tahmin etmede vWF'nin en iyi kesme değeri ROC analizi ile belirlendi (Şekil 1). Buna göre, vWF düzeyinin $\geq 128$ olmasının yüksek GS'yi öngördürmedeki sensitivitesi $\% 59$, spesifitesi $\% 63$ olarak tespit edildi (eğri altındaki alan: $0.643, \% 95$ güven aralığı: 0.550-0.737, $P=0,003$ ).

\section{Tartışma}

Inflamasyon AKS patogenezinde çok önemli bir rol oynar. Inflamasyonun değerlendirilmesinde geleneksel olarak en sık kullanılan laboratuvar parametreleri CRP, ESH ve BK'dir. VWF de, inflamasyonun değerlendirilmesinde kullanılabilecek proinflamatuvar belirteçlerden biridir. Çalışmamızın ana bulgusu, AKS ile başvuran hastalarda yüksek plazma vWF seviyesinin yüksek GS ile bağımsız bir şekilde ilişkili olduğudur.

Tablo 2. Çalışmaya alınan hastaların biyokimyasal ve ekokardiyografik özelliklerinin karşılaştırıması

\begin{tabular}{|c|c|c|c|}
\hline & $\begin{array}{l}\text { Grup 1 } \\
(n=73)\end{array}$ & $\begin{array}{l}\text { Grup } 2 \\
(n=68)\end{array}$ & $P$ \\
\hline Hemoglobin (gr/l) & $13(12-14)$ & $12(13-15)$ & 0.184 \\
\hline Beyaz küre $\left(10^{3} / \mu \mathrm{L}\right)$ & $9.7(7-12.3)$ & $10.5(8-15)$ & 0.032 \\
\hline $\begin{array}{l}\text { Eritrosit sedimentas- } \\
\text { yon hızı }(\mathrm{mm} / \mathrm{h})\end{array}$ & $14(10-23)$ & 20 (14-29) & 0.007 \\
\hline Platelet $\left(10^{3} / \mu \mathrm{L}\right)$ & $219(181-280)$ & $231(183-286)$ & 0.516 \\
\hline $\begin{array}{l}\text { C- reaktif protein } \\
(\mathrm{mg} / \mathrm{dL})\end{array}$ & $11(4-37)$ & $20(9-52)$ & 0.038 \\
\hline $\begin{array}{l}\text { Total } \quad \text { kolesterol } \\
(\mathrm{mg} / \mathrm{dl})\end{array}$ & $186(156-225)$ & 178 (149-211) & 0.491 \\
\hline $\begin{array}{l}\text { Düşük dansiteli } \\
\text { kolesterol }(\mathrm{mg} / \mathrm{dl})\end{array}$ & 116 (89-152) & $111(76-136)$ & 0.174 \\
\hline $\begin{array}{l}\text { Yüksek dansiteli } \\
\text { kolesterol (mg/dl) }\end{array}$ & $37(31-45)$ & $36(31-42)$ & 0.503 \\
\hline Trigliserid (mg/dl) & 127 (99-179) & 147 (104-194) & 0.110 \\
\hline $\begin{array}{l}\text { von Willebrand } \\
\text { faktör (IU) }\end{array}$ & $120(100-134)$ & $140(101-149)$ & 0.010 \\
\hline $\begin{array}{l}\text { Sol ventrikül erejek- } \\
\text { siyon fraksiyon (\%) }\end{array}$ & $55(42-61)$ & $50(44-60)$ & 0.344 \\
\hline $\begin{array}{l}\text { Sol ventrikül enddi- } \\
\text { astolik çap (mm) }\end{array}$ & $52(48-57$ & $55(50-58)$ & 0.137 \\
\hline $\begin{array}{l}\text { Sol ventrikül endsis- } \\
\text { tolik çap (mm) }\end{array}$ & $36(31-42)$ & 39 (34-43) & 0.094 \\
\hline $\begin{array}{l}\text { İnterventriküler } \\
\text { septum kalınlığı } \\
(\mathrm{mm})\end{array}$ & $11(10-14)$ & $11(10-14)$ & 0.846 \\
\hline
\end{tabular}

Tablo 3. Gensini skoru ile laboratuvar parametreleri arasındaki korelasyon analizi sonuçları

$\begin{array}{lcc}\text { Değişkenler } & r & p \\ \text { vWF } & 0.228 & 0.007 \\ \text { Eritrosit sedimentasyon hızı } & 0.222 & 0.010 \\ \text { C-reaktif protein } & 0.151 & 0.078 \\ \text { Beyaz küre } & 0.164 & 0.052\end{array}$

vWF: Von willebrand faktör

Gensini skoru, koroner arter hastalığının yaygınlığını ve ciddiyetini değerlendirmek için kullanılan anjiyografik bir skorlama sistemidir (11). Yapılan çalışmalarda, perkütan koroner girişim yapılan AKS hastalarında GS'nin 1 yıllık kardiyak ölüm, miyokard enfarktüsü ve hedef damar revaskülarizasyonunun bağımsız bir belirleyicisi olduğu gösterilmiştir (13). Bu nedenle, bu skorlama sistemi AKS hastalarında yaygın olarak kullanılan bağımsız bir prognostik belirteç olarak kabul edilmektedir. 
Tablo 4. Gensini skorunun bağımsız öngördürücülüğünü gösteren çok değişkenli lojistik regresyon analizi

OR (\% 95 güven aralığı)

\begin{tabular}{lll}
\hline Yaş & $1.008(0.964-1.037)$ & 0.646 \\
VKI & $1.005(0.930-1.087)$ & 0.987 \\
Hipertansiyon & $1.743(0.768-3.957)$ & 0.184 \\
Diyabet & $0.585(0.226-1.515)$ & 0.270 \\
Sigara & $1.874(0811-4.329)$ & 0.142 \\
Beyaz küre & $1.074(0.982-1.175)$ & 0.117 \\
ESH & $1.022(1.000-1.046)$ & 0.055 \\
CRP & $1.001(0.996-1.006)$ & 0.660 \\
VWF & $1.018(1.003-1.032)$ & 0.015 \\
\hline
\end{tabular}

VKI: Vücüt kitle indeksi, ESH: Eritrosit sedimentasyon hızI,

CRP: C-reaktif protein, vWF: von Willebrand faktör

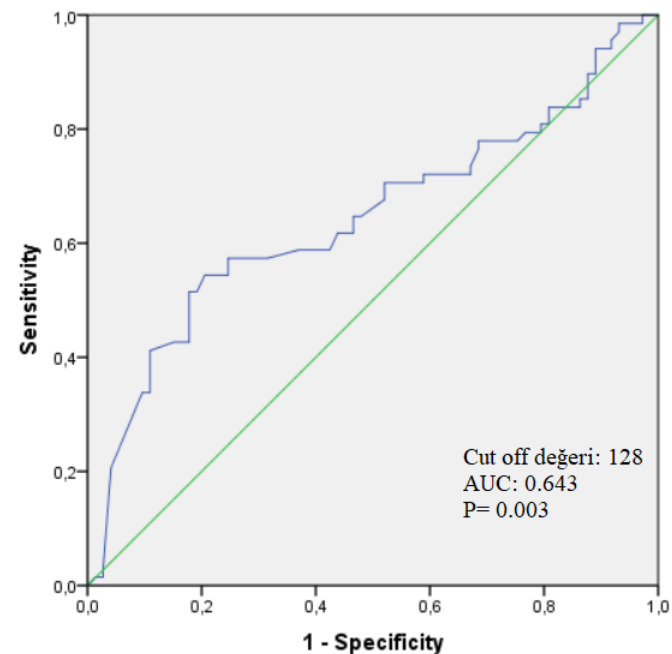

Şekil 1: von Willebrand faktörünün Yüksek gensini skorunu öngördürmedeki ROC curve analizi

İnflamasyon, aterosklerozis sürecinde kritik bir öneme sahiptir. Atereoskleroz sürecindeki endotel disfonksiyonu, lökosit göçü, hücre dışı matris bozulması ve trombosit aktivasyonu gibi bir çok aşama, lokal inflamasyonun etkisinden kaynaklanmaktadır (2). vWF; kan viskozitesine, trombosit agregasyonuna ve trombus oluşumuna katkıda bulunan ve hem inflamasyon hem de koagülasyon belirteci olarak kullanılan bir glukoproteindir (4). vWF bunlara ek olarak, düz kas hücre proliferasyonunu arttırıp, endotel hücre reseptörlerine bağlanarak vazoaktif mediatörlerin salımını tetikler ve endotel disfonksiyonuna yol açar (3-4). Bozulmuş endotel fonksiyonu aterogenez için en önemli risk faktörü olduğundan dolayı, vWF'nin de ateroskleroz sürecinde önemli bir rolü olduğu söylenebilir. Nitekim yapılan birçok çalışmada artmış vWF düzeyinin olumsuz kardiyovasküler olaylar ile ilişkili olduğu gösterilmiştir (1315).

Akut koroner sendrom ile inflamasyon belirteçleri arasındaki ilişki ortaya koyan birçok çalışma vardır (16-18). Çalışmamızda da literatür ile uyumlu olarak daha yaygın koroner arter hastalığı bulunan (GS $\geq 32$ ) AKS'li hastalarda CRP, ESH ve BK'nin anlamlı olarak daha yüksek olduğunu tespit ettik. Çalışmamızda bu çalışmalara ek olarak, koroner arter hastalığı yaygınlığı ve vWF arasındaki iliş̧i de incelenmiş ve daha yaygın koroner arter hastalığı bulunan AKS'li hastalarda vWF düzeyinin de anlamlı olarak daha yüksek olduğu tespit edilmiştir. Ek olarak, GS ile vWF düzeyi arasında pozitif yönde bir korelasyon olduğunu tespit ettik. Dahası, vWF ve diğer tüm inflamatuvar parametreleri dâhil ettiğimiz çok değişkenli lojistik regresyon analizinde, vWF'nin yüksek GS'yi öngördüren tek bağımsız belirleyicisi olduğunu bulduk. Elde ettiğimiz bu bulgular, AKS hastalarında vWF'nin koroner arter hastalığı yaygınlığını öngördürmede diğer inflamatuvar belirteçlere daha yüksek bir klinik öneme sahip olduğunu düşündürmektedir. Dolayısıyla başvuru anında daha yüksek vWF düzeyine sahip olan AKS hastalarında koroner arter hastalığı yaygınlığının ve ciddiyetinin daha fazla olduğu sonucuna varılabilir.

\section{Çalışmanın Sınırlııkları}

Çalışmamızın bazı kısıtlııkları mevcuttu. Birincisi tek merkezli ve görece az sayıda hasta ile yapılmasıdır. İkinci olarak, koroner angiyografik değerlendirmenin görsel yorumlama ile yapılmasıdır. Üçüncü olarak, sadece bazal vWF seviyeleri değerlendirildi. Seri vWF ölçümleri yapmak daha faydalı olabilirdi. Ayrıca, koroner arter hastalığının yaygınlığı ve ciddiyetinin göstergesi olan diğer skorlamalar ile karşılaştırma yapılması makelemize daha fazla katkı sağlayabilirdi.

\section{Sonuç}

Akut koroner sendromlu hastalarda başvuru anındaki yüksek von Willebrand faktör seviyesi bağımsız olarak yüksek gensini skoru ile ilişkilidir..

\section{Kaynaklar}

1. David E. Gutstein, Valentin Fuster. Pathophysiology and clinical significance of atherosclerotic plaque rupture Cardiovascular Research. $1999:$ ( 41)323-33.

2. Kolansky, D.M. Acute coronary syndromes: Morbidity, mortality, and pharmacoeconomic burden. Am. J. Manag. Care. 2009; 15: 36-41.

3. Whincup PH, Danesh J, Walker M, Lennon L, Thomson A, Appleby $\mathrm{P}$, et al. von Willebrand factor and coronary heart disease: prospective study and meta-analysis. Eur Heart J. 2002;23(22):1764-70.

4. Pottinger BE, Read RC, Paleolog EM, Higgins PG, Pearson JD. von Willebrand factor is an acute phase reactant in man. Thromb Res. 1989;53(4):387-94. 
5. Folsom AR, Wu K, Rosamond WD, Sharret AR, Chambless LE. Prospective study of hemostatic factors and incidence of coronary heart disease: the Atherosclerosis Risk in Communities (ARIC) Study. Circulation. 1997; 96: 1102-8.

6. Smith FB, Lee AJ, Fowkes FGR, Rumley A, Lowe GDO. Hemostatic factors as predictors of ischemic heart disease and stroke in the Edinburgh Artery Study. Arterioscler Thromb Vasc Biol. 1997; 17: 3321-5.

7. Rumley A, Lowe GDO, Sweetnam PM, Yarnell JWG, Ford RP. Factor VIII, von Willebrand factor and the risk of major ischaemic heart disease in the Caerphilly Heart Study. $\mathrm{Br} \mathrm{J}$ Haematol. 1999; 105: 110-6.

8. Thögersen AM, Jansson JH, Boman K, Nilsson TK, Weinehall L, Huhtasaari $F$, et al. High plasminogen activator inhibitor and tissue plasminogen activator levels in plasma precede a first acute myocardial infarction in both men and women: evidence for the fibrinolytic system as an independent primary risk factor. Circulation. 1998;98(21):2241-7

9. Meade TW, Cooper JA, Stirling Y, Howarth DJ, Ruddock V, Miller GJ. Factor VIII, ABO blood group and the incidence of ischaemic heart disease. Br J Haematol. 1994; 88: 601-7.

10. Tascanov MB, Tanriverdi Z, Gungoren F, Besli F, Erkus ME, Gonel A, et al. Association between the No-Reflow Phenomenon and Soluble CD40 Ligand Level in Patients with Acute STSegment Elevation Myocardial Infarction. Medicina (Kaunas). 2019;55(7).

11. Gensini, G.G. A more meaningful scoring system for determining the severity of coronary heart disease. Am J Cardiol. 1983; 51: 606.

12. Zhou BY, Guo YL, Wu NQ, Zhu CG, Gao Y, Qing P, et al. Free triiodothyronine in relation to coronary severity at different ages: Gensini score assessment in 4206 euthyroid patients. J Geriatr Cardiol. 2016;13(12):978-83.

13. Zencirci $A E$, Zencirci $E$, Degirmencioglu $A$, Karakus G, Ugurlucan M, Gunduz S, et al. The relationship between Gensini score and ST-segment resolution in patients with acute ST-segment elevation myocardial infarction undergoing primary percutaneous coronary intervention. Kardiol Pol. 2014;72(6):494-503.

14. Danesh J, Lewington S. Plasma homocysteine and coronary heart disease: systematic review of published epidemiological studies. J Cardiovasc Risk. 1998; 5:229-32.

15. Ross R. Atherosclerosis an inflammatory disease. $N$ Engl $\mathrm{J}$ Med. 1999;340:115-20.

16. Dursun, İ. Taşcanov MB. Akut ST Elevasyonlu Miyokard Enfarktüslü Hastalarda Aritmiler. Cukurova Med J. 2019; 44: 416-24.

17. Tanriverdi Z, Colluoglu T, Dursun H, Kaya D. The Relationship between neutrophil-to-lymphocyte ratio and fragmented QRS in acute STEMI patients treated with primary PCI. J Electrocardiol. 2017; 50:876-83.

18. Kiliç T, Ural E, Oner G, Sahin T, Kiliç M, Yavuz S, et al. Which cut-off value of high sensitivity $C$ - reactive protein is more valuable for determining long- term prognosis in patients with acute coronary syndrome?. Anadolu Kardiyol Derg. 2009;9(4):280-9. 